J. Lake Sci.(湖泊科学), 2019, 31(3): 779-787

DOI 10. 18307/2019. 0316

(c) 2019 by Journal of Lake Sciences

\title{
平原河网地区人类活动对降雨-水位关系的影响一一太湖流域杭 嘉湖地区为例”
}

\author{
王杰,许有鹏 ${ }^{* *}$, 王跃峰, 王 强,袁甲,高斌, 项 捷,代晓颖 \\ (南京大学地理与海洋科学学院, 南京 210023)
}

\begin{abstract}
摘 要: 太湖流域快速城镇化、水利工程等一系列人类活动对流域水文过程产生了深刻影响. 本文以快速城镇化的杭嘉 湖地区为例,基于 1961-2014 年逐日降雨、水位观测资料,构建了水位涨幅 $(\Delta Z)$ 、水位增长速率 $\left(k_{1}\right)$ 和退水速率 $\left(k_{2}\right)$ 等指标, 旨在揭示变化环境下该地区降雨过程中水位的变化特征及可能的驱动因素. 结果表明:1) 变化环境下杭嘉湖地 区近 54 年降雨量呈微弱的增加趋势, 但降雨过程中的水位涨幅呈下降趋势, 尤其是平均水位涨幅呈显著下降趋势, 且于 2000 年左右发生明显变化; 突变后水位涨幅下降主要集中在 $10 \sim 50 \mathrm{~mm} / \mathrm{d}$ 的降雨过程中, 而大于 $50 \mathrm{~mm} / \mathrm{d}$ 的降雨过程中 突变后水位涨幅较突变前有所升高. 2) 从空间分布上来看,各站降雨量与水位涨幅存在明显的空间差异,降雨量总体呈 增加趋势, 增加趋势东强西弱; 大部分站点的水位涨幅却呈下降趋势, 其中位于区域南部站点的平均水位涨幅下降趋势 较东北部更为明显, 水位涨幅呈显著下降站点的空间分布与杭嘉湖南排工程等水利工程的分布较为一致. 3 ) 通过对杭嘉 湖地区降雨过程中水位增长速率和退水速率的变化分析发现, 突变后较突变前退水速率有所提高, 说明近年来水利工程 等设施的完善和有序调度使得杭嘉湖地区的排洪能力有所提高, 该变化可能是导致杭嘉湖地区地区突变后一定强度的 降雨过程中水位涨幅下降的主要原因. 而杭嘉湖地区强降雨过程中水位涨幅依然较高, 可能是该地区洪峰水位居高不下 的主要原因. 此外,由于该地区近年来起涨水位抬升明显,对洪峰水位的抬升也有一定影响.
\end{abstract}

关键词: 太湖流域;杭嘉湖地区;平原河网地区;水位涨幅;水位增长速率;退水速率

Impacts of anthropogenic activity on the response of water level to rainfall in the urbanized plain river network: A case study in the Hangzhou-Jiaxing-Huzhou region of Taihu Basin

WANG Jie, XU Youpeng ${ }^{* *}$, WANG Yuefeng, WANG Qiang, YUAN Jia, GAO Bin, XIANG Jie \& DAI Xiaoying

(School of Geographic and Oceanographic Sciences, Nanjing University, Nanjing 210023, P.R.China)

Abstract: Rapid urbanization and human activities have a profound impact on the hydrological process in Taihu Basin. This paper constructed three indices include the water level rising $(\Delta Z)$, the rate of water level rising $\left(k_{1}\right)$ and the rate of water level recession $\left(k_{2}\right)$. Based on the observation data of daily rainfall and water level during 1961-2014, we try to reveal the variation characteristics of the water level and possible driving factors in the rainfall process in the Hangzhou-Jiaxing-Huzhou region. The results indicate that: (1) The rainfall shows an increasing trend, but the $\Delta Z$ shows a decreasing trend during the rainfall process. Especially, the average water level rising shows a significant decreasing trend and the abrupt change occurs in the year 2000 AD. The decreased $\Delta Z$ mainly occurs in the rainfall intensity ranged from $10 \mathrm{~mm} / \mathrm{d}$ to $50 \mathrm{~mm} / \mathrm{d}$ after 2000 AD. The $\Delta Z$ shows an increased trend in heavy rainfall process above $50 \mathrm{~mm} / \mathrm{d}$. (2) The rainfall in the east shows a significantly increasing trend than in the west. However, $\Delta Z$ in many stations is declining, which is more significant in the south. These changes is inseparable from the flood discharge project in the Hangzhou-Jiaxing-Huzhou region. (3) Through the analysis of the $k_{1}$ and $k_{2}$ in the rainfall process, $k_{2}$ is increased, which indicates that the development of water conservancy facilities and orderly scheduling has improved the flood dis-

* 国家重点研发计划项目(2016YFC0401502)、国家自然科学基金项目 (41771032) 和江苏水利基金重大项目 (2015003) 联合资助. 2018-08-04 收稿;2018-11-15 收修改稿. 王杰( 1989 ), 男, 博士研究生;E-mail: geowangjie@ 163.com.

** 通信作者;E-mail: xuyp305@163.com. 
charge capacity in recent years. This change may be the main cause for the declined $k_{2}$ in a certain intensity of rainfall after 2000 AD. The $\Delta Z$ remained high in the heavy rainfall process, which can be related to that the current flood discharge capacity that cannot resist the increase of $\Delta Z$. In addition, the incipient rising water level has increased significantly in recent years, which also makes a certain impact on the flood in the study area.

Keywords: Taihu Basin; Hangzhou-Jiaxing-Huzhou region; plain river network; the water level rising; the rate of water level rising; the rate of water level recession

太湖流域平原河网地区作为我国城市化程度较高的区域之一, 洪涝灾害历来是造成该地区经济损失最 为严重的自然灾害之一 ${ }^{[1-3]}$. 近年来随着城市化进程的不断推进, 河道结构简化、河道调蓄能力显著下降, 导 致平原河网地区应对洪涝灾害的能力进一步减弱 ${ }^{[4]}$. 水位作为洪旱灾害预警和洪涝灾害防御工程建设中设 计洪水的基础要素, 其变化对区域洪旱灾害防御及防洪工程的质量与精度有重要影响 ${ }^{[5-7]}$. 近年来平原河网 地区随着人类活动等因素的加剧影响, 使得太湖流域平原河网地区河道水位发生了显著变化 ${ }^{[8-9]}$. 尤其是水 利工程调度, 严重改变了湖泊、河道和圩区水位的变化过程, 导致水位对降雨的响应发生显著变化, 同时水 位变化对以水位频率为基础的区域防洪标准的制定产生影响 ${ }^{[10]}$. 因此, 在变化环境下研究太湖流域平原河 网地区降雨与水位的响应关系, 不仅可以揭示太湖流域平原河网地区应对洪涝灾害的能力, 还可以反映该 区水利工程运行调度对降雨与水位响应关系的影响.

已有对太湖流域水位及降雨与水位关系的研究主要集中在太湖水体上,而对平原河网地区水位变化的 研究较少. 陆琛莉等 ${ }^{[11]}$ 应用物理量曲面拟合的方法对环太湖地区 1960-1995 年间降雨量和水位的关系进 行分析, 结果显示当月降水量与下月的太湖水位有着很好的相关性; 刘汶等 ${ }^{[12]}$ 利用水文一水动力学模型预 测了太湖流域未来时段中不同下垫面变化下的水位变化情况,认为未来太湖流域最高水位和平均水位较基 准期 (1961- 1990 年) 均显著升高, 因此未来发生大洪灾的可能性将会增加; 尹义星等 ${ }^{[13]}$ 对太湖腹部武澄锡 虞区和阳澄淀泖区水位变化做了研究, 发现极值水位呈上升趋势, 极值水位与历年降水的变化之间存在差 异; Song 等 ${ }^{[8]}$ 对秦淮河地区水位变化做了分析, 发现随着城市化的不断发展, 城市不透水面积显著增加, 河 网结构明显简化, 导致秦淮河地区水位上升明显; 徐光来等 ${ }^{[9]}$ 对杭嘉湖平原区水位变化做了分析, 杭嘉湖地 区降雨变化不明显, 而水位却呈增加趋势, 且平均水位和最低水位变化尤为明显, 该变化与人类活动有重要 关系.

现有研究多基于对观测降雨和水位数据的分析, 虽然在洪涝灾害的预警中起到重要作用, 但未考虑平 原河网地区变化情况下起涨水位变化对降雨水位响应关系的影响. 因此, 在研究降雨水位的响应关系时沿 用河道水位的观测值与降雨量之间的关系必然会导致分析结果的精确性受到影响. 本文在揭示杭嘉湖孕灾 环境变化的基础上, 旨在揭示太湖流域平原河网地区高度城市化与大型水利工程运行调度等强烈人类活动 的综合影响下降雨水位的变化规律. 为了避免降雨前期水位变化对降雨一水位响应关系的影响, 本文仅考虑 降雨过程中河道水位涨幅的变化,基于此开展杭嘉湖地区降雨水位的关系分析. 同时,依据降雨与水位的突 变特征对突变前后降雨过程中水位涨幅、水位增长速率和退水速率进行对比分析, 从中揭示太湖流域平原 河网地区变化环境对降雨水位关系的影响机制.

\section{1 数据与方法}

\section{1 研究区概况}

杭嘉湖地区 $\left(30^{\circ} 09^{\prime} \sim 31^{\circ} 02^{\prime} \mathrm{N} 、 119^{\circ} 52^{\prime} \sim 121^{\circ} 16^{\prime} \mathrm{E}\right)$ 北邻太湖、南接钱塘江、西至浙西丘陵区、东临黄浦 江, 面积约为 $7607 \times 10^{4} \mathrm{~km}^{2}$, 区内地势较低, 平均海拔为 $1.6 \sim 2.2 \mathrm{~m}$, 是典型的平原河网地区 (图 1). 又由于 杭嘉湖地区位于亚热带季风气候区, 降水频繁, 使得洪涝灾害极易发生. 近年来随着该区城市化进程的不断 发展, 下垫面发生了显著变化, 截止 2010s 杭嘉湖地区城镇用地增加至 $3009.39 \mathrm{~km}^{2}$, 较 $1990 \mathrm{~s}$ ( 1991 年) 增加 了 $2655.98 \mathrm{~km}^{2}$ (表 1). 城镇用地大量增加, 以侵占耕地 (水田和旱地) 为主, 水田面积减少约 $2904.38 \mathrm{~km}^{2}$. 下 垫面变化也对该地区水系格局变化产生了影响 ${ }^{[14]}$, 水系数量、结构以及复杂度均有所下降, 其中河网密度和 水面率分别下降了 $0.31 \mathrm{~km} / \mathrm{km}^{2}$ 和 $1.12 \%$, 支流发育系数和干流面积长度比分别下降了 0.89 和 $1.37 \mathrm{~km}^{2} / \mathrm{km}$ (表 1). 城市化过程中不透水面积增加, 导致径流系数增大, 严重影响了该地区产汇流过程. 同时城市化扩 
张侵占大量耕地和水系,使得区域可调蓄洪涝的空间逐渐减小,增加了洪涝风险程度 ${ }^{[15]}$. 自 1991 年大洪水 之后, 治太工程相继开展, 近年来杭嘉湖地区先后修建了太嘉河、平湖塘延伸拓俊、环湖河道整治和扩大杭 嘉湖南排等大型引排水工程 (图 1), 工程整治拓宽河道、修建大型水闸和葲站,其在抵御洪涝灾害中作用显 著 ${ }^{[16-17]}$. 如杭嘉湖南排工程, 其作为杭嘉湖地区涝水的主要排泄渠道,包括长山闸、南台头闸、盐官上河闸和 盐官枢纽等,节制闸总设计流量为 $2257 \mathrm{~m}^{3} / \mathrm{s}$, 在 2013 年强台风“菲特” 期间, 累计排水 5.6 亿 $\mathrm{m}^{3}$, 有效降低 了嘉兴水位. 因此,在变化环境下,探讨快速城市化及大型水利工程调度等人类活动综合影响下杭嘉湖地区 降雨水位的响应关系,有助于揭示城市化和水利工程作用对该地区洪涝灾害的影响.

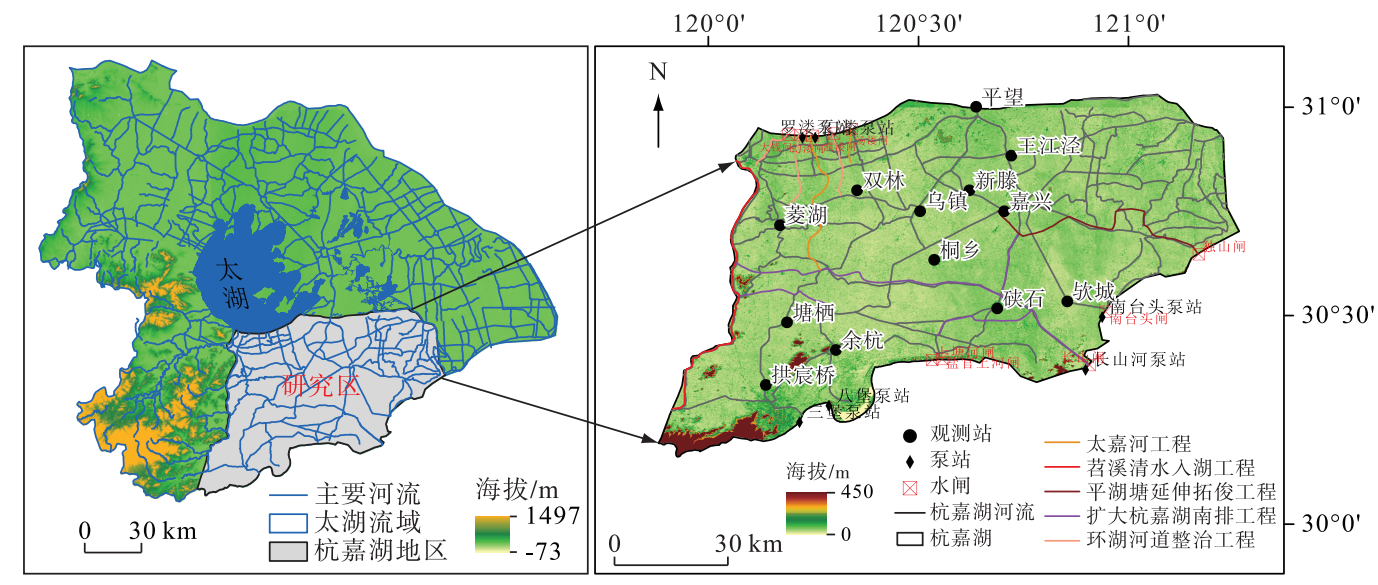

图 1 研究区概况

Fig.1 Location of the Hangzhou-Jiaxing-Huzhou region

表 1 杭嘉湖地区土地利用/覆被变化和水系结构的变化量

Tab.1 Variation of the LULC and streams structure in the Hangzhou-Jiaxing-Huzhou region

\begin{tabular}{cccccccc}
\hline 土地利用类型 & $1990 \mathrm{~s}$ & $2010 \mathrm{~s}$ & 变化量 & 水系结构参数 $[14]$ & $1980 \mathrm{~s}$ & $2010 \mathrm{~s}$ & 变化量 \\
\hline 城镇 $/ \mathrm{km}^{2}$ & 353.41 & 3009.39 & 2655.98 & 河网密度 $/\left(\mathrm{km} / \mathrm{km}^{2}\right)$ & 3.24 & 2.93 & -0.31 \\
水域 $/ \mathrm{km}^{2}$ & 632.57 & 982.98 & 350.41 & 水面率 $/ \%$ & 9.88 & 8.76 & -1.12 \\
早地 $/ \mathrm{km}^{2}$ & 729.77 & 582.84 & -146.93 & 支流发育系数 & 2.83 & 1.94 & -0.89 \\
林草地 $/ \mathrm{km}^{2}$ & 159.19 & 204.09 & 44.9 & 干流面积长度比 $/\left(\mathrm{km}^{2} / \mathrm{km}\right)$ & 47.03 & 45.66 & -1.37 \\
水田 $/ \mathrm{km}^{2}$ & 5740.1 & 2835.72 & -2904.38 & 盒维数 & 1.64 & 1.58 & -0.06 \\
\hline
\end{tabular}

\section{2 数据获取与研究方法}

1.2.1 数据来源 观测数据包括雨量站降雨数据和主干河流水位数据. 依据降雨与水位监测的同步性以及 时间序列的完整性, 同时考虑到降雨的空间分布存在差异, 选取杭嘉湖地区具有相同监测位置的 13 个代表 站降雨量和水位数据开展该地区降雨水位响应关系研究, 时间序列为 1961-2014 年.

土地利用数据来源于研究区 1991 年和 2015 年两期 Landsat TM 和 $\mathrm{ETM}^{+}$遥感影像解译结果. 土地利用 分类参考中国土地资源分类系统, 并根据研究区土地利用类型特点, 将原土地利用数据类型分为草地、林 地、园地、滩涂、旱地、城镇、水田和水体 8 个类别, 最后依据本文研究目的将土地类别合并归类为旱地、城 镇、水田、水域和林草地 5 大类别. 结合野外调研数据、地形图和高分辨率遥感影像验证表明,1991 年分类精 度为 $82.94 \%$, Kappa 系数为 $0.78 ; 2015$ 年分类精度为 $87.91 \%$, Kappa 系数为 0.84 , 表明分类结果较为可信, 可 用上述数据开展土地利用变化研究.

水系数据主要依据不同时期的地形图,通过遥感影像解译和实地考察对地形图中水系数据进行校核获 得. 杭嘉湖地区 $1980 \mathrm{~s}$ 的水系数据由 $1: 5$ 万纸质地形图通过扫描、配准、数字化、拓扑检验和拼接等获得. $2010 \mathrm{~s}$ 的水系图通过 1:5万数字线划地图获得. 通过叠加不同时期的水系图对比分析研究区水系的时间 


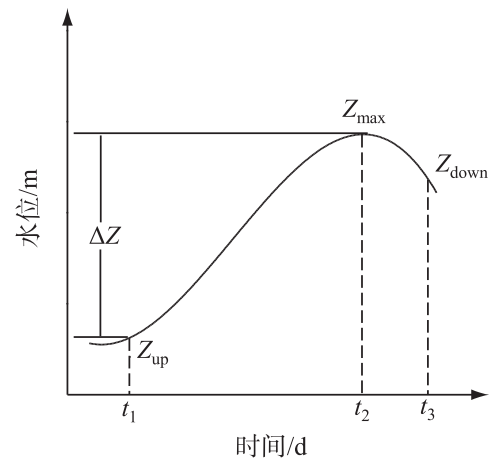

图 2 洪水演变过程

Fig. 2 The flood routing process

变化.

1.2.2 研究方法 河流水系变化特征主要体现在数量、形态和结构 特征的变化, 本文参考以往城市化背景下平原河网地区水系特征参 数与表征指标的基础上 ${ }^{[14]}$, 选取了河网密度、水面率、支流发育系 数、干流面积长度比和盒维数共 5 个指标来定量描述城镇化下河流 水系的变化特征. 另外, 由于杭嘉湖地区水位受多重因素的影响, 在 分析降雨水位响应关系时, 为了避免降雨前期水位变化对其响应过 程的影响, 分别统计了 1961-2014 年期间逐次降雨过程 (图 2) 中 的水位涨幅 $(\Delta Z)$ 、平均水位涨幅 $(\Delta \bar{Z})$ 、水位增长速率 $\left(k_{1}\right)$ 和退水 速率 $\left(k_{2}\right)$ 等指标的变化特征. 各指标计算公式分别为:

$$
\begin{aligned}
\Delta Z & =Z_{\text {up }}-Z_{\text {max }} \\
\Delta \bar{Z} & =\frac{100 \times \Delta Z}{P} \\
k_{1} & =\frac{Z_{\text {max }}-Z_{\text {up }}}{t_{2}-t_{1}}
\end{aligned}
$$$$
k_{2}=\frac{Z_{\max }-Z_{\text {down }}}{t_{3}-t_{2}}
$$

式中, $Z_{\text {up }}$ 为起涨水位; $Z_{\text {max }}$ 为峰值水位; $Z_{\text {down }}$ 为峰值水位起后续 3 日水位; $t_{1}$ 为起涨水位时刻; $t_{2}$ 为峰值水 位时刻; $t_{3}$ 为峰值水位后第 3 日水位时刻; $P$ 为场次降雨过程中的降雨总量.

\section{2 结果分析}

\section{1 变化环境下降雨量与水位涨幅的变化}

2.1 .1 降雨量与降雨过程中水位涨幅的年际变化 研究时段内杭嘉湖地区降雨量呈上升趋势 (图 3a), 降雨 过程中年水位涨幅以 $-0.01 \mathrm{~m} / \mathrm{a}$ 的速率下降 (图 $3 \mathrm{~b}$ ), 两者均未通过 0.05 的显著性水平检验. 而平均水位涨 幅呈显著下降趋势 (图 3c). 从 M-K 突变检验的结果可以看出 (图 3d、e、f), 近 54 年降雨量突变出现在 1980 年和 2000 年左右, 而水位涨幅和平均水位涨幅的突变均出现在 2000 年左右. 可以看出, 突变后杭嘉湖年水 位涨幅和平均水位涨幅较突变前均有明显下降.
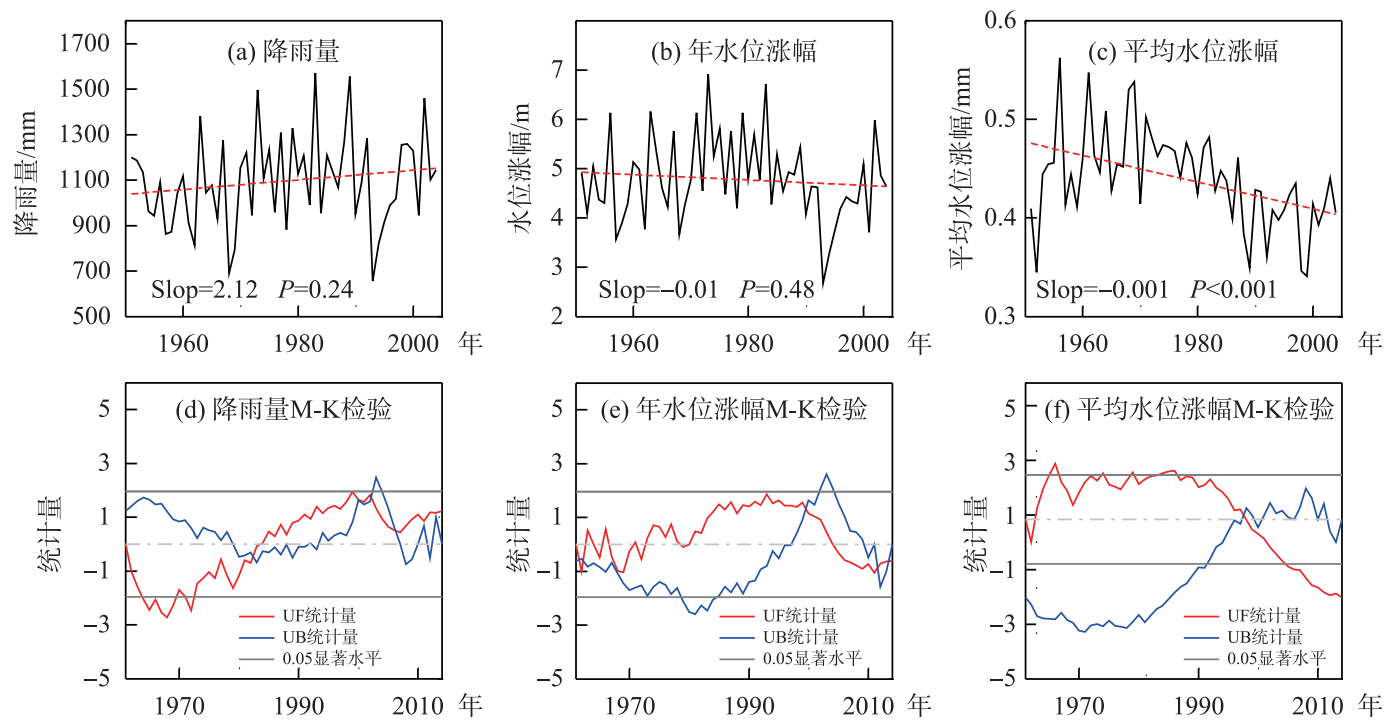

图 3 1961－2014 年杭嘉湖地区降雨与水位的时间变化

Fig.3 Variation of rainfall and water level in the Hangzhou-Jiaxing-Huzhou region during 1961-2014 
从近 54 年杭嘉湖地区降雨量的空间分布可以看出, 降雨量以增加趋势为主, 但各站点的增加幅度并不 一致,整体呈自东向西呈减弱的空间分布特征 (图 4a); 降雨过程中的年水位涨幅整体呈减少趋势, 尤其是位 于杭嘉湖南部的部分站点的年水位涨幅减少趋势较为明显 (图 4b), 而东北部年平均水位涨幅呈显著的增 加趋势 $(P<0.05)$; 杭嘉湖地区平均水位涨幅整体呈减少趋势, 位于杭嘉湖地区南部的部分站点的平均水位 涨幅呈显著的减少趋势 $(P<0.05)$ ( 图 4c). 从空间分布格局可以看出, 位于杭嘉湖南排工程、平湖塘延伸拓 俊工程及杭州市附近站点年水位涨幅和平均水位涨幅却呈显著的下降趋势. 该变化可能与杭嘉湖南排工程 和平湖塘延伸拓俊工程及杭州市南排葲站提高区域排洪除涝能力有关.
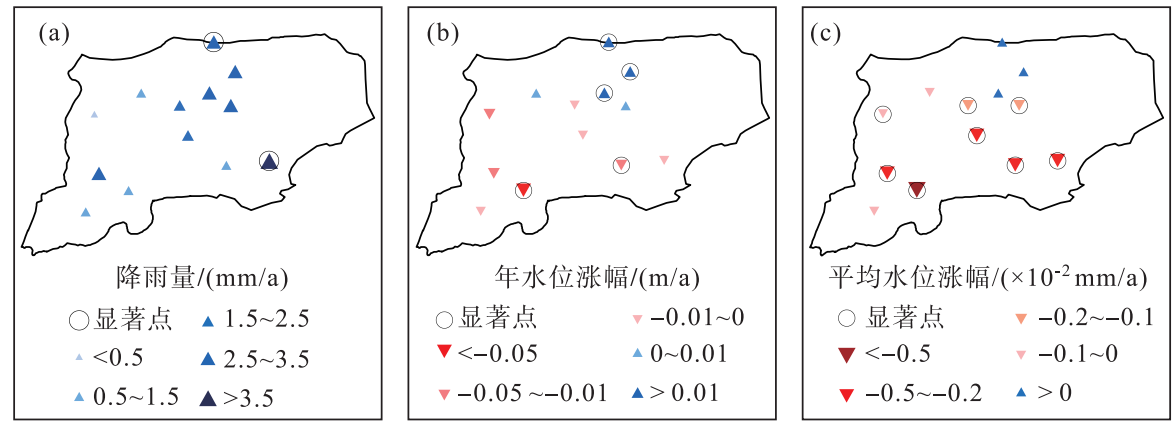

图 4 杭嘉湖地区降雨量倾向率和水位涨幅倾向率的空间变化

Fig.4 Spatial distribution of trend magnitude of annual rainfall and water level rising in the Hangzhou-Jiaxing-Huzhou region

2.1.2 不同降雨过程中水位涨幅的变化 为了进一步探讨杭嘉湖地区降雨过程中水位涨幅下降这一现象, 本 文对突变前后水位增涨幅进行了分级比较, 按照日降雨强度将降雨过程分为小雨 $(R<10 \mathrm{~mm})$ 、中雨 $(10 \mathrm{~mm} \leqslant$ $R<25 \mathrm{~mm}$ )、大雨 $(25 \mathrm{~mm} \leqslant R<50 \mathrm{~mm})$ 和暴雨 $(R \geqslant 50 \mathrm{~mm}) 4$ 个等级, 分别统计了不同强度降雨过程中水位涨 幅变化情况. 如图 5a 所示, 杭嘉湖地区突变前后不同等级降雨过程中水位涨幅有明显变化,小于 $10 \mathrm{~mm} / \mathrm{d}$ 的降雨过程中水位涨幅差异不明显; $10 ~ 50 \mathrm{~mm} / \mathrm{d}$ 的降雨过程中, 水位涨幅突变后较突变前有所下降; 而大 于 $50 \mathrm{~mm} / \mathrm{d}$ 的强降雨过程中突变后水位涨幅较突变前有所升高. 同时, 对城区 (包括嘉兴、余杭、拱宸桥、桐 乡和硖石) 和乡镇站 (包括平望、塘栖、菱湖、双林、乌镇、歌城、王江泾和新滕) 不同等级降雨过程中水位涨幅 的变化情况进行分析, 发现城区和乡镇地区不同降雨过程中水位涨幅与全区变化特征基本一致(图 5b、c). 由此可见,杭嘉湖地区水位涨幅下降主要体现在降雨强度小于 $50 \mathrm{~mm} / \mathrm{d}$ 的降雨过程中, 而大于 $50 \mathrm{~mm} / \mathrm{d}$ 的 强降雨过程中水位涨幅不减反增.

\section{2 变化环境下降雨过程中水位增长速率和退水速率的变化}

2.2.1 水位增长速率的变化 由于杭嘉湖地区突变前后降雨过程中水位涨幅的差异较为明显, 对突变前后水 位增长速率进行了对比分析. 由图 6a 可见, 杭嘉湖地区降雨过程中水位增长速率随降雨强度的增加而升 高, 降雨强度小于 $10 \mathrm{~mm} / \mathrm{d}$ 的降雨过程中水位增长速率差异不大, 降雨强度为 $10 \sim 50 \mathrm{~mm} / \mathrm{d}$ 的降雨过程中 突变后水位增长速率小于突变前水位增长速率, 而大于 $50 \mathrm{~mm} / \mathrm{d}$ 的降雨过程中突变后水位增长速率较突变 前有所升高; 城区站降雨强度小于 $10 \mathrm{~mm} / \mathrm{d}$ 的降雨过程中突变前后水位增长速率几乎没有变化, 降雨强度 在 $10 \sim 50 \mathrm{~mm} / \mathrm{d}$ 的降雨过程中突变前水位增长速率大于突变后水位增长速率, 最大差异仅为 $0.03 \mathrm{~m} / \mathrm{d}$, 而 $50 \mathrm{~mm} / \mathrm{d}$ 以上降雨过程突变后水位增长速率与突变前差异较大, 约为 $0.04 \mathrm{~m} / \mathrm{d}$, 且增加幅度远高于全区平 均水平 (图 6b, 表 2); 乡镇站水位增长速率与城区变化较为相似, 但大于 $50 \mathrm{~mm} / \mathrm{d}$ 水位增加速率较城区有所 降低 (图 6c). 由此可见, 不同强度降雨过程中水位增长速率与水位涨幅变化较为一致, $10 \sim 50 \mathrm{~mm} / \mathrm{d}$ 的降雨 过程中突变后水位增长速率有所降低, 导致水位涨幅相应下降; 大于 $50 \mathrm{~mm} / \mathrm{d}$ 的强降雨过程中, 突变后水位 增长速率有所提高,使得该地区水位涨幅亦相应升高.

2.2.2 退水速率的变化 杭嘉湖地区退水速率的变化可以反映该地区河流的排洪能力, 由于降雨过程中退水 速率取证较为困难, 为了反映杭嘉湖地区河流的排洪能力, 对近 54 年逐次降雨结束后水位达到峰值起后续 

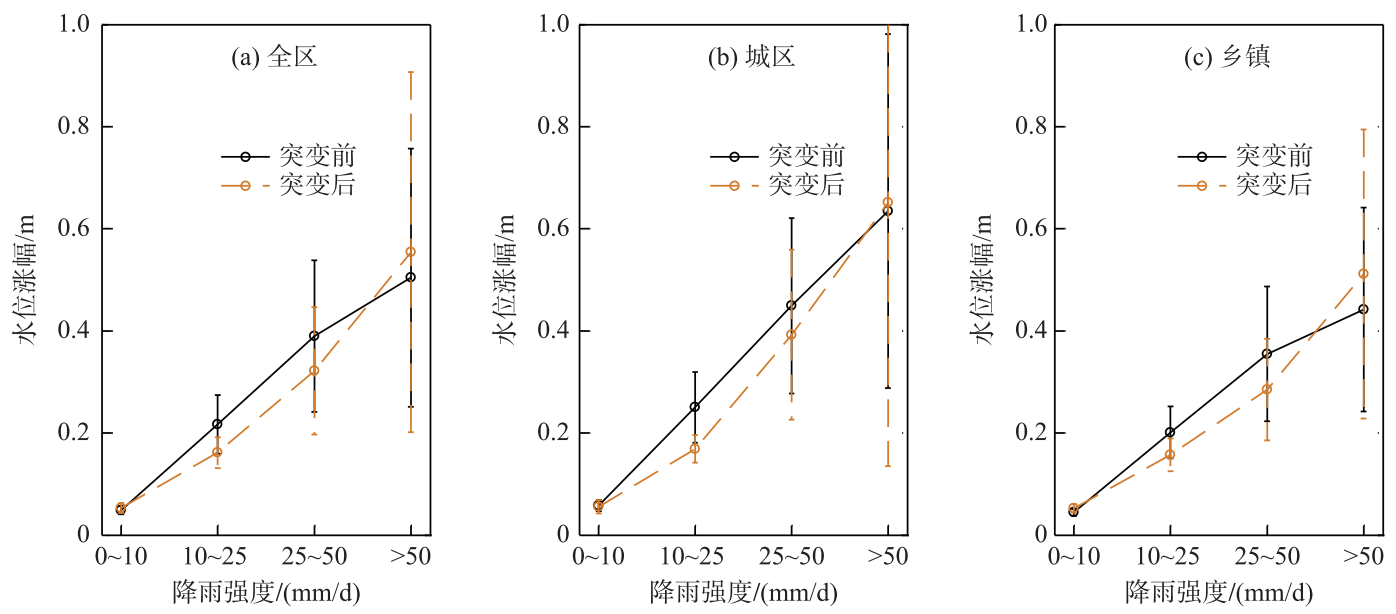

图 5 不同等级降雨过程中水位涨幅变化

Fig. 5 Change of the water level rising in different rainfall processes
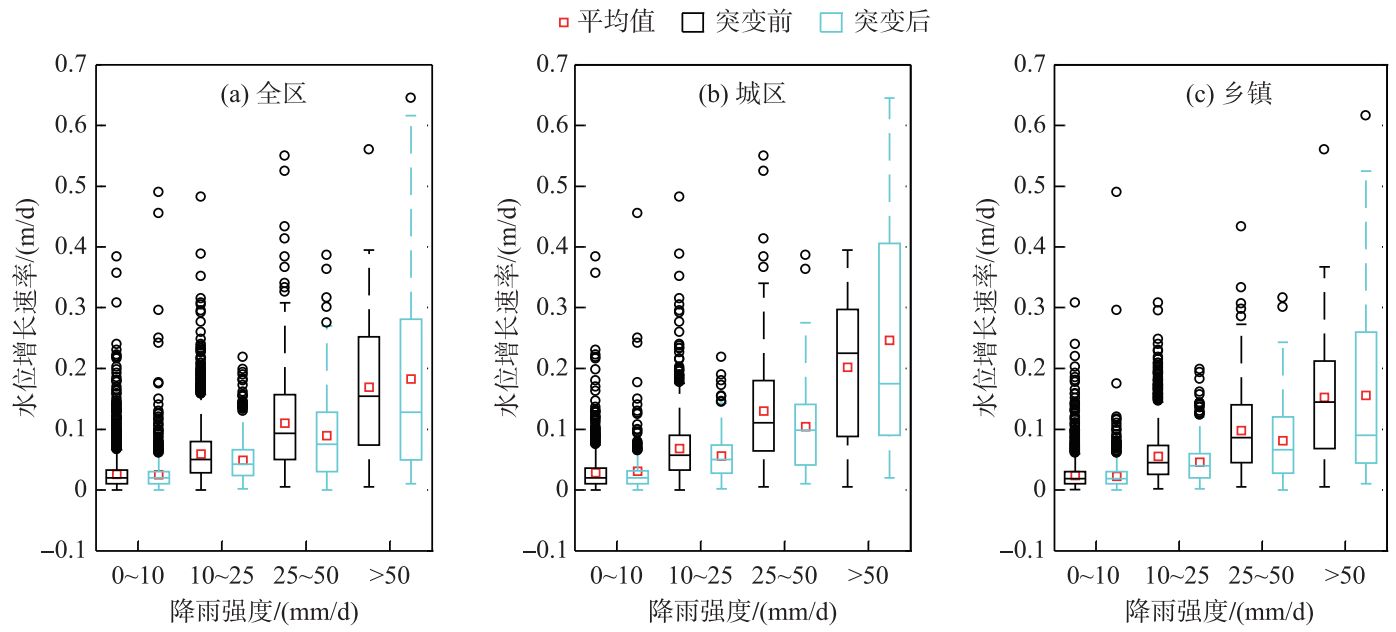

图 6 杭嘉湖地区不同降雨强度下水位增长速率

Fig. 6 The rate of water level rising in different rainfall intensities in the Hangzhou-Jiaxing-Huzhou region

表 2 杭嘉湖地区水位增长速率与退水速率

Tab. 2 The rate of water level rising and recession in the Hangzhou-Jiaxing-Huzhou region

\begin{tabular}{|c|c|c|c|c|c|c|}
\hline \multirow{2}{*}{$\begin{array}{c}\text { 降雨强度/ } \\
(\mathrm{mm} / \mathrm{d})\end{array}$} & \multicolumn{3}{|c|}{$\begin{array}{c}\text { 水位增长速率突变 } \\
\text { 前后差 } /(\mathrm{m} / \mathrm{d})\end{array}$} & \multicolumn{3}{|c|}{$\begin{array}{c}\text { 退水速率突变前后 } \\
\text { 差 } /(\mathrm{m} / \mathrm{d})\end{array}$} \\
\hline & 全区 & 城区 & 乡镇 & 全区 & 城区 & 乡镇 \\
\hline$<10$ & 0 & 0 & 0 & 0 & 0 & 0 \\
\hline $10 \sim 25$ & 0.01 & 0.01 & 0.01 & 0 & 0 & 0 \\
\hline $25 \sim 50$ & 0.02 & 0.03 & 0.02 & -0.01 & -0.01 & -0.01 \\
\hline$>50$ & 0.01 & 0.04 & 0 & -0.02 & -0.02 & -0.03 \\
\hline
\end{tabular}

3 日水位的退水速率进行分析, 如图 7a 所示, 杭嘉湖 地区不同强度降雨结束后退水速率随着降雨强度的 增加呈升高趋势, 突变前后降雨强度小于 $25 \mathrm{~mm} / \mathrm{d}$ 的降雨过程退水速率差异较小, 而降雨强度大于 25 $\mathrm{mm} / \mathrm{d}$ 的降雨过程退水速率差异逐渐增大, 其中降雨 强度大于 $50 \mathrm{~mm} / \mathrm{d}$ 的降雨过程退水速率差异可达 $0.02 \mathrm{~m} / \mathrm{d}$ (表 2); 城区与乡镇地区均表现出类似的变 化特征, 但城区不同强度的降雨过程中水位的退水 速率均高于乡镇地区的退水速率 (图 7b、c). 该变化 与城区防洪措施更加完善有关, 由于近年来随着水 利工程不断投人使用和防洪工程的优化协调, 极大 
地提高了城区的排洪能力 ${ }^{[18]}$. 如: 2013 年强台风 “菲特” 期间, 杭嘉湖南排工程全力排水,共计排水 5.6 亿 $\mathrm{m}^{3}$, 使嘉兴站水位从 $2.58 \mathrm{~m}$ 退至 $1.30 \mathrm{~m}$, 河网槽蓄量减少了 3.79 亿 $\mathrm{m}^{3[16]}$. 因此, 杭嘉湖地区水利工程的运 行有效提高了该区的退水速率.

\section{3 讨论}

水位变化受区域产水能力、河道调蓄能力、水利工程调度和潮位顶托等因素共同影响. 随着城市化的不 断发展, 不透水层面积大大增加, 导致杭嘉湖地区河网水系衰减明显 ${ }^{[15]}$. 同时, 杭嘉湖地区河道水位受海平 面上升及潮位的顶托作用显著,不易于杭嘉湖地区洪涝的排泄. 而大坝、圩区、水闸和洜站等水利工程的修 建以及河道疏浚拓宽等有助于提高杭嘉湖地区的排洪能力和河道的调蓄能力 ${ }^{[16-19]}$. 杭嘉湖西部山区建有大 中型水库 15 座, 总库容为 11.23 亿 $\mathrm{m}^{3}$,防洪库容 4.81 亿 $\mathrm{m}^{3}$, 能够有效拦截杭嘉湖西部山区来水; 同时杭嘉 湖东部平原地区建有 5 项大型引排水工程 (图 1), 胡尧文 ${ }^{[20]}$ 通过一维水动力数学模型模对工程实施前、后 断面水位变化进行了研究, 发现疏通了大钱港、罗溇、幻溇、兴溇和汤溇等主要人湖河道, 使得太湖水体较为 流畅地进人杭嘉湖东部平原腹部, 平原河网最低水位较工程实施前均有提高, 如嘉兴站最低水位升高了约 $0.05 \mathrm{~m}$; 而通过南排闸门引排调度, 平原河网最高水位则较施工前有所降低, 嘉兴站最高水位降低了约 0.11 m. 本文通过水位退水速率的变化分析也印证了这一结论,杭嘉湖地区水位突变后退水速率均有所提高, 尤 其是降雨强度大于 $50 \mathrm{~mm} / \mathrm{d}$ 的降雨过程退水速率差异可达 $0.03 \mathrm{~m} / \mathrm{d}$, 说明近年来水利工程的完善和有序调 度使得杭嘉湖地区应对不同强度降雨时的排洪能力有所提高, 且有效抑制了城市化导致的河网水系衰减等 对该区洪涝调蓄能力的影响. 此外, 排洪能力提高有助于揭示杭嘉湖地区降雨过程中水位涨幅下降的真实 原因,正是由于排洪能力的提高有效抑制了降雨过程中水位增长速率, 使得杭嘉湖地区突变后同等降雨过 程中水位涨幅在降雨强度小于 $50 \mathrm{~mm} / \mathrm{d}$ 的降雨过程中有所下降. 然而强降雨过程中退水速率虽有提高, 但 不能够完全抑制该地区水位增长, 从而使得降雨强度大于 $50 \mathrm{~mm} / \mathrm{d}$ 的降雨过程中突变后水位涨幅依然有所 升高. 因此有必要进一步完善该地区水利工程建设以及提高水利工程的优化调度, 以应对强降雨过程所产 生的洪水对该地区的潜在威胁.
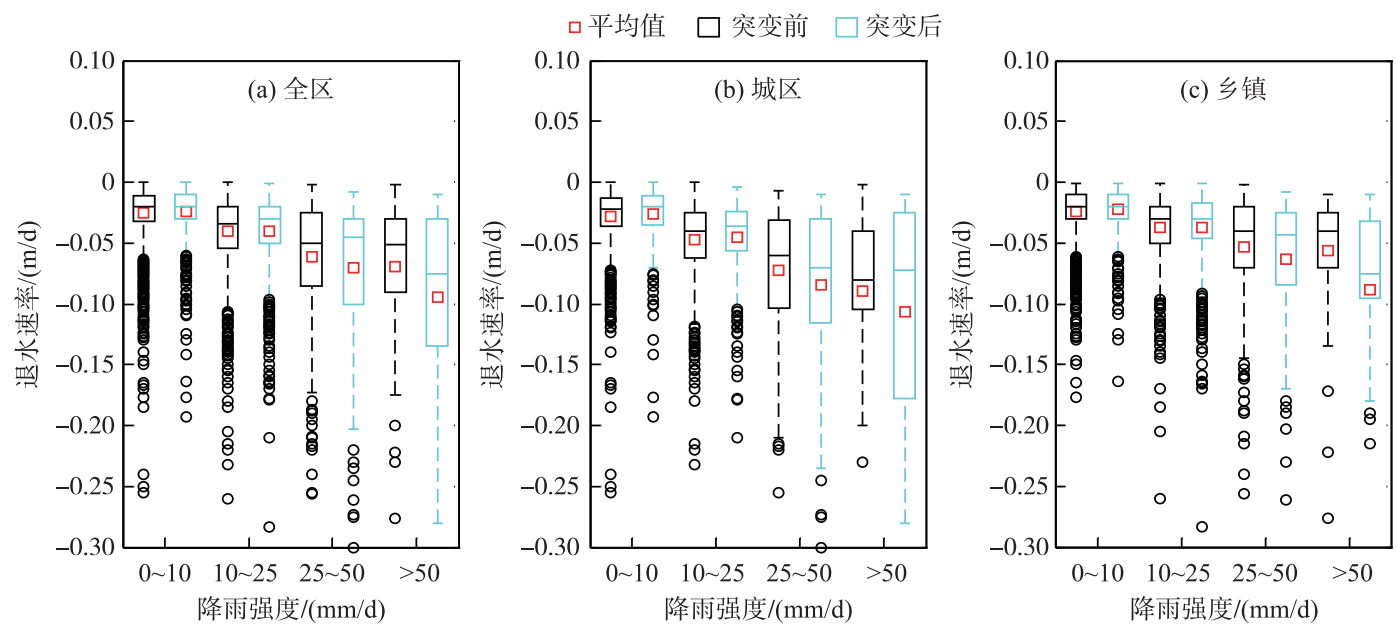

图 7 杭嘉湖地区不同降雨强度下退水速率

Fig.7 The rate of water level recession in different rainfall intensities in the Hangzhou-Jiaxing-Huzhou region

此外,近年来杭嘉湖地区排洪能力有所提高, 使得降雨过程中水位涨幅虽有下降, 但杭嘉湖地区洪峰水 位依然呈上涨趋势 ${ }^{[9]}$. 鉴于水位是起涨水位与降雨过程中水位涨幅的叠加, 水位的变化不仅受水位涨幅变 化的影响, 同时起涨水位对水位变化也有一定影响 ${ }^{[21]}$. 杭嘉湖地区强降雨过程中水位涨幅有所升高, 同时 “引江济太” 等引排水工程因疏通了河道, 提高了太湖流域水体的流畅性, 使得该地区起涨水位也有升 


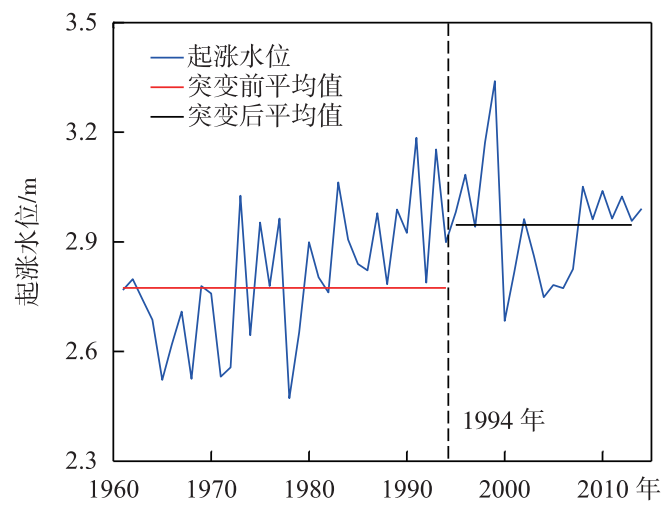

图 8 杭嘉湖地区起涨水位的时间变化

Fig. 8 Change of incipient rising water level in the Hangzhou-Jiaxing-Huzhou region
高 $^{[22-23]}$ (图 8). 因此, 强降雨过程中洪峰水位居高不下 与水位涨幅和起涨水位的抬升有必然的联系.

\section{4 结论}

1) 近 54 年杭嘉湖地区降雨量呈微弱的增加趋势, 降雨过程中水位涨幅不增反降, 同时平均水位涨幅呈 显著的下降趋势 $(P<0.01)$. 通过 $M-K$ 突变分析发现， 降雨与水位响应关系出现显著变化的时间节点在 2000 年左右.

2) 从空间分布格局看, 杭嘉湖地区降雨量以增加 趋势为主, 东部增加趋势较西部更为明显, 而降雨过程 中水位涨幅基本呈微弱的减少趋势; 平均水位涨幅也 呈减少趋势, 尤其是杭嘉湖南部的减少趋势更为明显, 该变化与杭嘉湖南排工程等在排洪除涝过程中起到的 作用密不可分.

3) 通过对比分析突变前后不同等级降雨过程中水 位涨幅的变化情况可以看出, 杭嘉湖地区水位涨幅下降主要集中在 $10 \sim 50 \mathrm{~mm} / \mathrm{d}$ 的降雨过程中, 而大于 50 $\mathrm{mm} / \mathrm{d}$ 的强降雨过程中水位涨幅有所升高.

4) 杭嘉湖地区降雨过程中水位增长速率变化并不一致, 降雨强度小于 $10 \mathrm{~mm} / \mathrm{d}$ 的降雨过程中水位增长 速率差异并不明显, 降雨强度为 $10 \sim 50 \mathrm{~mm} / \mathrm{d}$ 降雨过程中突变后水位增长速率较突变前有所降低, 而降雨 强度大于 $50 \mathrm{~mm} / \mathrm{d}$ 的降雨过程中突变后水位增长速率较突变前有所升高. 同时城区和乡镇地区水位增长速 率与全区变化特征基本一致; 退水速率随着降雨强度的增加呈增加趋势, 降雨强度小于 $25 \mathrm{~mm} / \mathrm{d}$ 的降雨过 程中突变前、后退水速率基本无差异, 而大于 $25 \mathrm{~mm} / \mathrm{d}$ 的降雨过程中突变后退水速率有明显的升高. 退水速 率的升高说明杭嘉湖地区的排洪能力有所提高, 该变化正是导致杭嘉湖地区降雨过程中水位涨幅下降的主 要原因. 虽然排洪能力的提高很大程度上抑制了降雨过程中水位涨幅, 但该区应对强降雨的能力依然有待 提高.

\section{5 参考文献}

[ 1 ] Li W, Maren DSV, Wang ZB et al. Peak discharge increase in hyperconcentrated floods. Advances in Water Resources, $2014,67(4): 65-77$.

[ 2 ] He B, Huang X, Ma M et al. Analysis of flash flood disaster characteristics in China from 2011 to 2015. Natural Hazards, 2019, $90(1): 407-420$.

[ 3 ] Hu ZJ, Wang LL, Tang HW et al. Prediction of the future flood severity in plain river network region based on numerical model: A case study. Journal of Hydrodynamics, 2017, 29(4) : 586-595.

[ 4 ] Yuan W, Yang K, Tang M et al. Stream structure characteristics and their impact on storage and flood control capacity in the urbanized plain river network. Geographical Research, 2005, 24(5): 717-724. [袁雯, 杨凯, 唐敏等. 平原河网地 区河流结构特征及其对调蓄能力的影响. 地理研究, 2005, 24(5) : 717-724.]

[ 5 ] Zhang XQ, Pan L, Xu CY et al. Conditional value-at-risk for nonstationary streamflow and its application for derivation of the adaptive reservoir flood limited water level. Journal of Water Resources Planning and Management, 2018, 144 (3) : 04018005.

[ 6 ] Liu P, Li L, Guo S et al. Optimal design of seasonal flood limited water levels and its application for the Three Gorges Reservoir. Journal of Hydrology, 2015, 527: 1045-1053.

[ 7 ] Zhu Z, Dong Z, Yang W et al. Optimal operation research of flood retarding in plain river network region. Water, 2017, 9 (4) : 280 .

[ 8 ] Song S, Xu YP, Zhang JX et al. The long-term water level dynamics during urbanization in plain catchment in Yangtze 
River Delta. Agricultural Water Management, 2016, 174: 93-102.

[ 9 ] Xu GL, Xu YP, Luo X et al. Changes of water level induced by human activities at Hangzhou-Jiaxing-Huzhou plain in recent 50 years. Scientia Geographica Sinica, 2012, 32(10): 1262-1268. [徐光来, 许有鹏, 罗贤等. 近 50 年人类活动 引起的杭嘉湖平原区水位变化. 地理科学, 2012, 32(10): 1262-1268.]

[10] Xu XY, Zhang C, Shen XJ. Discussion of Taihu Basin flood control standards. J Lake Sci, 2006, 18(4) : 414-418. DOI: 10.18307/2006.0414. [徐向阳, 张超, 沈晓娟. 关于太湖流域防洪标准的讨论. 湖泊科学, 2006, 18 (4): 414-418. ]

[11] Lu CL, Fan BS, Zhu LF. Relation between precipitation around Taihu in the flood season and Taihu water level. Scientia Meteorologica Sinica, 2000, 20(1) : 51-56. [陆琛莉, 范柏松, 朱莲芳. 环太湖地区汛期降水量与太湖水位的关系. 气象科学, $2000,20(1): 51-56$.

[12] Liu L, Hu CW, Xu ZX et al. Application of scenario analysis technique on future water level foresight of the Taihu Lake. Journal of Hydraulic Engineering, 2012, 43(4): 404-413. [刘浏, 胡昌伟, 徐宗学等. 情景分析技术在未来太湖水 位预见中的应用. 水利学报, 2012, 43(4): 404-413.]

[13] Yin YX, Xu YP, Chen Y. Temporal and spatial changes of extreme water levels in the typical regions of Taihu Lake basin since the 1950s. Geographical Research, 2011, 30(6): 1077-1088. [尹义星, 许有鹏, 陈荣. 太湖流域典型区 50 年代 以来极值水位时空变化. 地理研究, 2011, 30(6) : 1077-1088.]

[14] Han LF, Xu YP, Yang L et al. Temporal and spatial change of stream structure in Yangtze River Delta and its driving forces during 1960s-2010s. Acta Geographica Sinica, 2015, 70(5): 819-827. [韩龙飞, 许有鹏, 杨柳等. 近 50 年长三 角地区水系时空变化及其驱动机制. 地理学报, 2015, 70(5):819-827.]

[15] Che Y, Yang K. Function the storage capacity of river network and mitigation of urban storm water disasters based on the consideration of traditional ecological wisdom. Acta Ecologica Sinica, 2016, 36(16): 4946-4948. [车越, 杨凯. 发挥河 网调蓄功能 消减城市雨洪灾害——基于传统生态智慧的思考. 生态学报, 2016, 36(16) : 4946-4948. ]

[16] Mao HP, Chen XC, Xu KW. Joint operation benefit analysis of the water diversion works of the Hangjiehu and Taipu Gate. Zhejiang Hydrotechnics, 2015, (3) : 94-96. [毛鸿鹏, 陈锡超, 许科文. 杭嘉湖南排工程与太浦闸工程联合调度效 益分析. 浙江水利科技, 2015, (3) : 94-96.]

[17] Xiang C, Wang YT, Shi GP. Evaluation on flood control and disaster reduction in Hangjiahu polder area. Journal of Zhejiang University of Water Resources and Electric Power, 2014, 26(1) : 29-32. [项春, 王益土, 施高萍. 杭嘉湖圩区防洪 减灾能力评价与提升对策研究. 浙江水利水电学院学报, 2014, 26(1): 29-32.]

[18] Zhong HY. The brief analysis on multipurpose dam project in flood control and water resource regulation. Water Resources Development Research, 2013, 4: 39-41. [ 钟惠钰. 浅析太湖流域控制性水利枢纽工程在防洪和水资源调度中的作 用. 水利发展研究, 2013, 4: 39-41.]

[19] Lin ZX. Construction of flood control engineering and countermeasures for flood disaster mitigation in Taihu basin. J Lake Sci, 2002, 14(1) : 12-18. DOI: 10.18307/2002.0102. [林泽新. 太湖流域防洪工程建设及减灾对策. 湖泊科学, $2002,14(1): 12-18$. ]

[20] Hu YW. Analysis of the effects of water diversion works for water environment improvement in the Hangjiehu District [Dissertation]. Hangzhou: Zhejiang University, 2010. [胡尧文. 杭嘉湖地区引排水工程改善水环境效果分析 [ 学位论 文]. 杭州: 浙江大学, 2010.]

[21] Hu CH, Zhang ZH. Research on variation of floodwater stage during the atrophy process of the Lower Yellow River channel. Journal of Hydraulic Engineering, 2012, 43(8) : 883-890. [胡春宏, 张治吴. 黄河下游河道萎缩过程中洪水水位变 化研究. 水利学报, 2012, 43(8):883-890.]

[22] Gao Y, Mao XW, Xu WD. Analysis of the influence on the Taihu lake and the area around diversion from the Yangtze river to the Taihu lake. Journal of China Hydrology, 2006, 26(1) : 92-94. [高怡, 毛新伟, 徐卫东. “引江济太”工程对太 湖及周边地区的影响分析. 水文, 2006, 26(1): 92-94.]

[23] Wu YK, Tao YG, Wang HY. Influence of “Diverting Changjiang river water into Taihu lake” engineering to Zhejiang. Zhejiang Hydrotechnics, 2007, (6) : 13-15. [伍远康, 陶永格, 王红英. “引江济太” 工程对浙江的影响分析. 浙江水 利科技, 2007, (6): 13-15.] 